\title{
Long-term vegetation change and its driving factors in a typical catchment of the Loess Plateau
}

\author{
C.L. Huang a,b (i) and Y.Q. Zhang ${ }^{c}$ \\ ${ }^{a}$ Northwestern University, Xi'an, Shaanxi, China, ${ }^{b}$ CSIRO Land \& Water, Canberra, ${ }^{c}$ Key Laboratory of Water \\ Cycle and Related Land Surface Processes, Institute of Geographic Sciences and Natural Resources Research, \\ The Chinese Academy of Sciences, Beijing 100101, China \\ Email: nwuhcl@163.com; yongqiang.zhang2014@gmail.com
}

\begin{abstract}
Vegetation information is critical for understanding terrestrial water and carbon dynamics, and is a key factor for regional environment management under climate change. This study selected a typical arid and semi-arid catchment, in the Loess Plateau, the Zuli River Basin (ZRB) to investigate the long-term vegetation cover change and its driving factors. Different from available Normalized Difference Vegetation Index (NDVI) products that were produced at coarse spatial resolutions and with short temporal ranges, high-resolution (30m) and long-term (31 years) NDVI data was generated in this study by using $30 \mathrm{~m}$ resolution Landsat dataset analyzed within the Google Earth Engine (GEE), a cloud platform with planetary-scale analysis capabilities. We evaluated the relationships between NDVI and precipitation, runoff coefficient and sediment concentration using cross wavelet, and explored the impact of precipitation on vegetation and the impact of vegetation cover on runoff and sediment before and after the implementation of Grain for Green Project (GGP, conservation program designed to mitigate and prevent flooding and soil erosion in China) in different parts of ZRB in 1956-2016. Our results show that there was an increasing trend in average maximum annual NDVI across the ZRB during 1987-2016 and a significantly $(p<0.05)$ increased trend in most areas. The vegetation cover increases in upstream Chankou and upstream Huining (two representative catchments within the ZRB) was higher than that in the middle stream and downstream, but with a smaller increase rate. Widespread increase in vegetation mostly occurred after GPP because the area with significant increase from 1987-2016was higher than the increased area in 1987-1999. The precipitation had significant correlation $(p<0.05)$ with NDVI series across the ZRB except for the upstream Chankou where human activities played a major role. The relationship between NDVI and the runoff coefficient, sediment concentration was significantly negative $(p<$ $0.05)$, which indicates that the vegetation cover is an important reason for reduction of runoff coefficient and sediment concentration. Meanwhile, the human activities also played a positive role on both restoration of vegetation and reduction of runoff coefficient and sediment concentration across the ZRB.
\end{abstract}

Keywords: Vegetation cover, Normalized Difference Vegetation Index, Grain for Green Project, precipitation, human activities 


\section{INTRODUCTION}

Vegetation is usually considered as an important indicator which can influence biodiversity and ecological process (Li et al., 2012) and a key medium in water and material cycling and energy balance ( Xin et al., 2008; Du et al., 2015). Over the past decades, the vegetation cover has experienced a notable change under global warming and increased human population, at regional and global scales (Pang et al., 2017). Hence, a comprehensive study of long-term vegetation cover change is important for better understanding of the spatial and temporal variation in landscapes and their beneficial to regulate regional ecosystem balance under environment changes in the past century (Fang et al., 2018).

Remote sensing techniques can detect vegetation cover dynamics quickly and accurately at various spatial and temporal scales (Wen et al., 2017; Chu et al., 2019). The Normalized Difference Vegetation Index (NDVI) is the most widely used remote sensing spectral index for detecting vegetation cover dynamics around the world (Robinson et al., 2017). For example, Du found that change rate of NDVI gradually decreased over three decades for growing season and all seasons in 1982-2012, this was detected using the Global Inventory Monitoring and Modelling System (GIMMS) NDVI dataset (Du et al., 2015). Zhao discovered a significant increase in annual and seasonal NDVI in the period of 2000 to 2014, based on the Moderate Resolution Imaging Spectroradiometer (MODIS) NDVI dataset, and claimed that the Grain for Green Project (GGP) had an important influence on vegetation dynamics, resulting in strong correlations between the cumulative afforestation area and annual NDVI in Yan'an and Yulin (Zhao et al., 2019).

The researches summarised above, are mainly based on coarse resolution images such as GIMMS-NDVI dataset and MODIS-NDVI dataset. Furthermore, most of them paid attention to the drivers of vegetation cover, and largely ignored the effects of vegetation cover change on runoff and sediment load. In addition, expansive changes in vegetation cover can have significant implications for physical and ecological processes (Bao et al., 2014; Huang et al., 2018), such as change in the surface energy balance, and impacts in soil erosion processes. Specifically, the improvement of vegetation cover not only decreases the streamflow through intercepting the overland flow and increasing infiltration time (Zhang et al., 2015), but also influences the sediment source in the catchment by reducing the kinetic energy of raindrops by an improved protective capability for soil surfaces (Duan et al., 2016). Keeping the above discussion in mind, this study concentrates on exploration of the effects of vegetation cover variation on runoff and sediment discharge over the past decades.

Besides, the Loess Plateau has the most severe soil erosion problem in China (McVicar et al., 2007; Liu et al., 2015; Cao et al., 2018). To control it, a series of soil and water conservation measures have been implemented, including slope improvement, management of gullies and small catchments (Cao et al., 2018). As a typical arid and semi-arid catchment in the Loess Plateau in China, Zuli River Basin (ZRB) has experienced severe soil erosion (Yao and Liu, 2018) and complex change in both vegetation cover and hydrologic processes in the past century due to climate change and complex human interpretation (Huang et al., 2018). So, it is necessary to understand the pattern, major drivers and implications of vegetation cover across the ZRB. Thus, the specific objectives of this study include: (1) assessing the spatiotemporal dynamics of vegetation dynamics from 1987-2016; (2) analysing the relationship between NDVI and precipitation; and (3) investigating the implications of vegetation cover changes on runoff and sediment discharge. 


\section{STUDY AREA AND METHODS}

The Zuli River, a tributary of the Yellow River, is located in the northwestern part of the Loess Plateau (104 ${ }^{\circ} 13^{\prime}$ $\sim 105^{\circ} 35^{\prime}$ E, $35^{\circ} 16^{\prime} \sim 36^{\circ} 34^{\prime} \mathrm{N}$ ), China (Figure 1). The catchment area and river length of Zuli River Basin (ZRB) is $10,647 \mathrm{~km}^{2}$ and $220 \mathrm{~km}$, respectively. The geographic area of ZRB belongs to the Third and Fifth Sub-region of the hilly and gully loess region with warm summers and cold and dry winters. The vegetation cover is low, and the annual soil erosion modulus reached up to $4710 \mathrm{t} / \mathrm{km}^{2}$, mainly caused by the water erosion and gravity erosion. Since the 1970s, a series of soil and water conservation structures, such as reservoirs and check-dams, were constructed in ZRB, and then the governance of gully and slope were deployed using control methods by combining engineering and vegetation measures. In order to analyse the vegetation distribution more accurately, we divide the whole catchment into four parts: upstream Chankou, upstream Huining, middle stream and downstream. The precipitation, in different parts, was obtained from the interpolation of point measurements. The runoff and sediment discharge data were obtained from the Hydrology Department of Gansu Province.
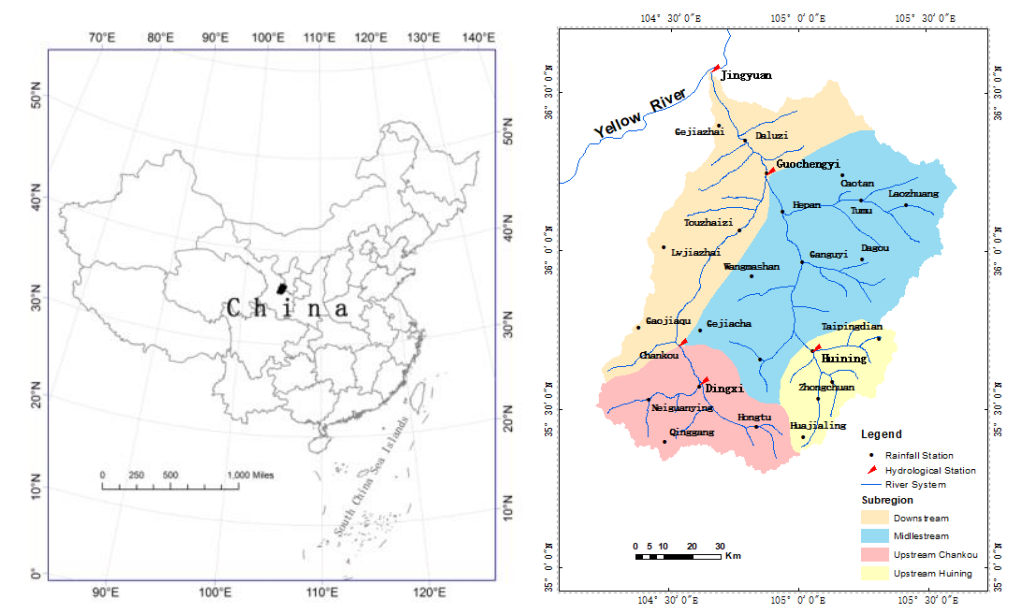

Figure 1. Location of the study area and stations of Zuli River Basin

In order to detect vegetation cover more accuracy and efficiently, we used Landsat-derived dataset developed on the Google Earth Engine (GEE) platform (Gorelick et al., 2017), and combined the wavelet method to detect causes and effects of vegetation cover change. Firstly, the catchment Landsat analysis was carried out using Landsat surface reflectance dataset based on the GEE a cloud-based large-scale computational facility for geospatial data analysis. The GEE includes the Landsat surface reflectance dataset that was atmospherically corrected from the Landsat 5 ETM, Landsat 7 ETM+ and Landsat 8 OLI/TIRS sensors. For this study, we analysed 22,794 Landsat scenes and proceeded them according following steps: (i) removing the cloud-cover pixels according to the pixel data quality of flag information; (ii) adding the band of NDVI for each image as per following equation:

$\mathrm{NDVI}=\frac{(N I R-R E D)}{(N I R+R E D)}$

where, NIR is surface reflectance in the near infrared band (band 4-Landsat 5, 7; band 5-Landsat 8) and RED is surface reflectance in the red band (band 3-Landsat 5, 7; band 4-Landsat 8); and (iii) combining all of Landsat derived NDVI and extracting NDVI according to study destination. Then, trends in NDVI were detected using the Sen's slope method and Pearson correlation method and regarded as a proxy of land degradation/improvement. Three categories were summarized as: (i) significant improvement (slope $>0$, P-value $<0.05$ ); (ii) Insignificant (slope $=0, \mathrm{P}$-value > 0.05); (iii) significant degradation (slope $<0$, P-value <0.05). Additionally, we applied the wavelet analysis with the F-test method to evaluate the relationship between vegetation cover, precipitation, runoff coefficient and sediment discharge.

\section{RESULTS}

\subsection{Changes in vegetation cover within Zuli River Basin}

The maximum yearly NDVI was used to detect the interannual variability of vegetation cover, which can reflect vegetation cover at the optimum level (Xin et al., 2011). The maximum yearly NDVI, in the different parts of ZRB, was extracted from high-resolution satellite images and plotted as the time series based on GEE from 1987 
to 2016 (Fig. 2A). The result shows that the annual maximum NDVI across the ZRB increased during 1987-2016 and the NDVI in the upstream ZRB was evidently higher than that in other parts of the catchment. There exists strong spatial heterogeneity in the vegetation cover, with NDVI varying from 0.15 in the downstream ZRB to 0.47 in the upstream ZRB. The large mean annual NDVI mainly appears in the upstream, the river area within middle and downstream and the edge of the southeastern ZRB. In contrast, there are low NDVI values in the middle and downstream of ZRB (Fig. 2B).
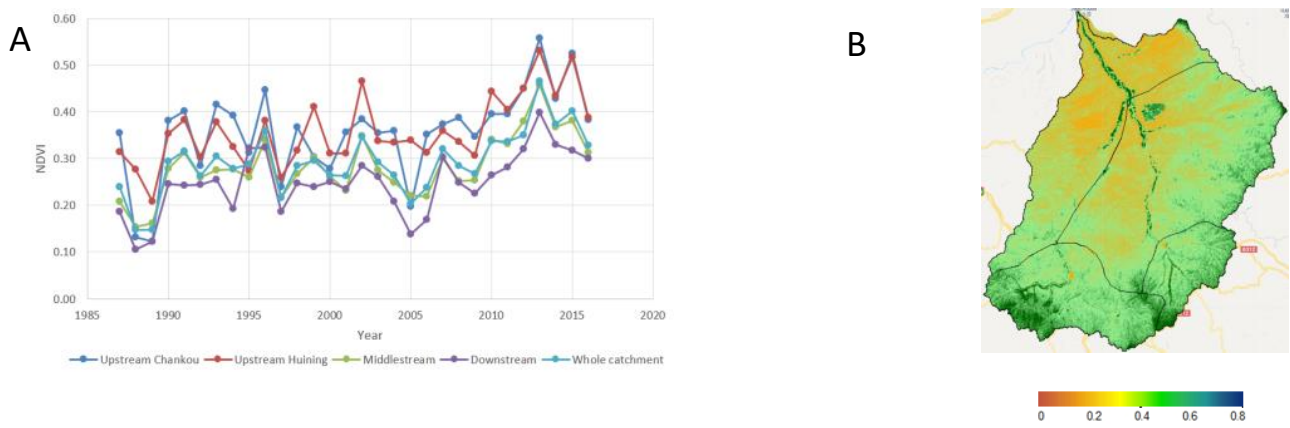

Figure 2. Interannual variations of annual maximum NDVI (A) in the different part of the ZRB from 19872016, and spatial pattern of the mean annual NDVI (B)

Further statistical analysis showed that most areas characterized by significantly increased NDVI during 19872016 (Fig. 3A). Moreover, the ZRB has experienced the insignificant increase in vegetation cover from 1987 to 1999, and the area with significant NDVI increase just accounts 3.64\%, 10.16\%, $0.08 \%$ and $0 \%$ for downstream, middlestream, upstream Chankou and upstream Huining, respectively (Fig.3E). The NDVI was largely increased after widespread soil and water conservation measures in 1999. Specifically, the areas characterized by significant increase in NDVI accounts for $30.09 \%, 12.89 \%, 14.01 \%, 5.92 \%$ in the middle, downstream, upstream Chankou and upstream Huining, respectively (Fig.3F), which is similar to the period of 1987-2016 (Fig. 3D).

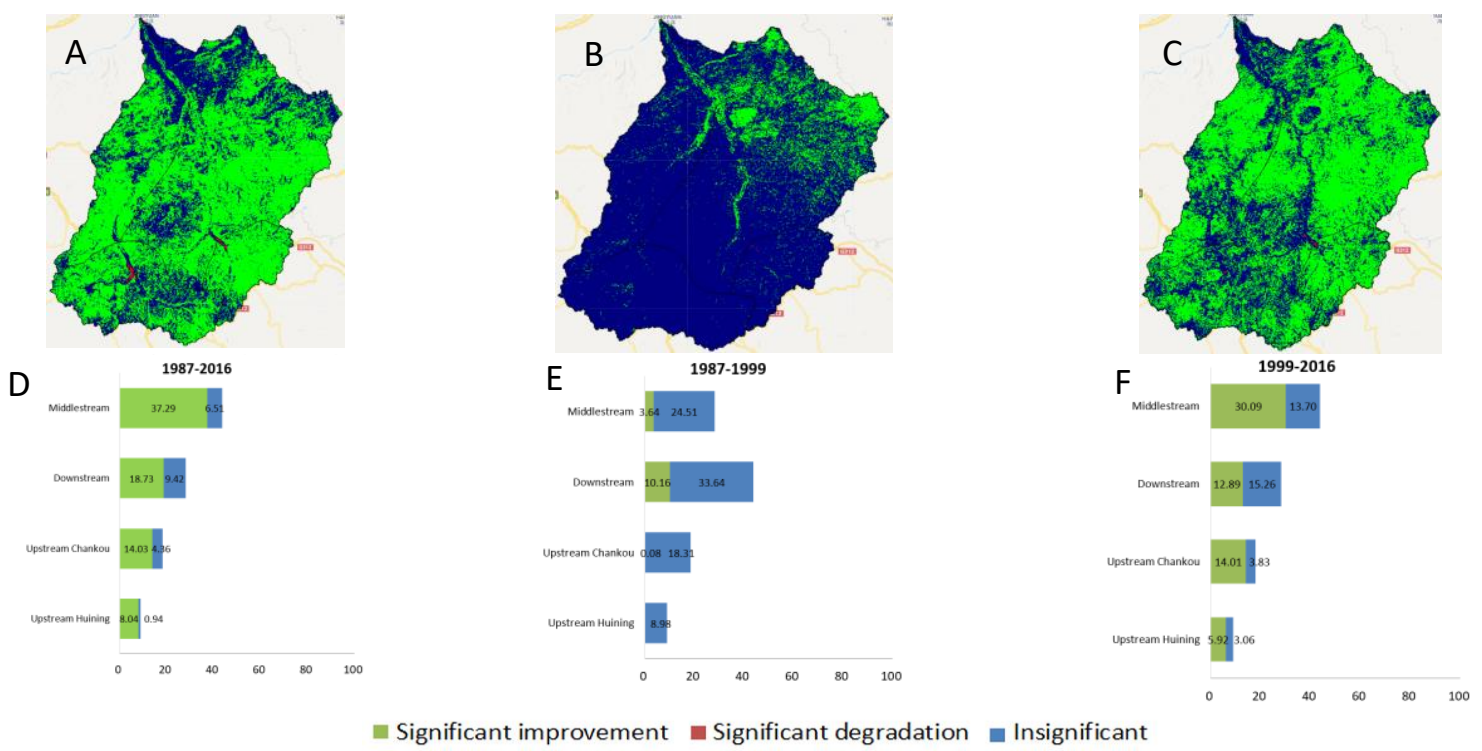

Figure 3. The trends distribution (significant level indicated by $\mathrm{p}<0.05)(\mathrm{A}, \mathrm{B}, \mathrm{C})$ and their statistical results $(\mathrm{D}$, E, F) in the Zuli River Basin from three stages: 1987 to 1999, 1987-1999 and 1999-2016

\subsection{Relationship between vegetation cover and precipitation}

In the past 60 years, the hydrometeorological condition from 1956 to 2016 changed strongly in different parts of ZRB. This is particularly the case for annual precipitation that was significantly decreased. In order to explore the relationship between vegetation and hydrometeorological condition in the past years, the wavelet analysis was applied in this study. 
The cross wavelet analysis with F-test found that there is no obvious correlation relationship between NDVI and precipitation in the Upstream Chankou. But in the other parts of the ZRB, the precipitation has a significantly negative correlation with NDVI with a signal of 1-3 years from 2001-2004 in the upstream Huining, and positive correlation with NDVI with a signal of 1-4 years 1996-2003 in middlestream ZRB, 2-4 years in 1994-2001 and 4-6 years in 2001-2012 in downstream ZRB (Figure 4 and Table 1).
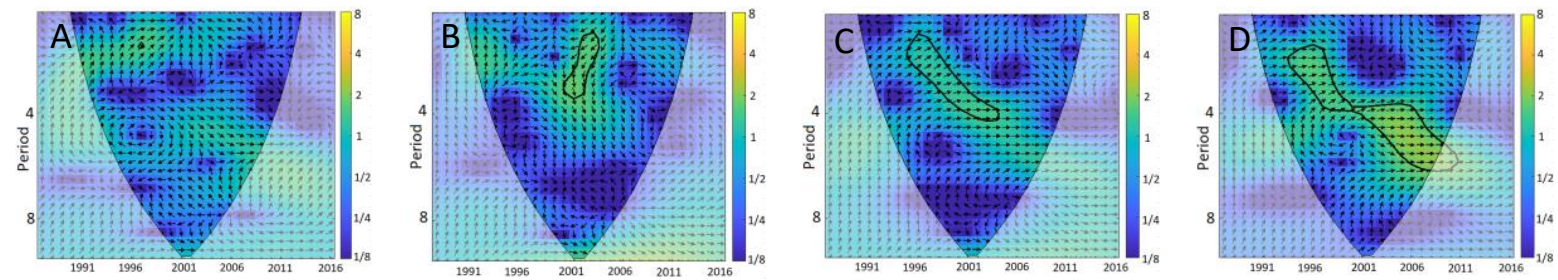

Figure 4. The relationship between annual maximum NDVI and precipitation detected by cross wavelet method in the different parts of the ZRB: (A) upstream Chankou; (B) upstream Huining; (C) middlestream; (D) downstream.

Table 1 The results of cross wavelet transforms between NDVI and precipitation, runoff and sediment

\begin{tabular}{|c|c|c|c|c|c|c|c|c|}
\hline & \multicolumn{2}{|c|}{ Upstream Chankou } & \multicolumn{2}{|c|}{ Upstream Huining } & \multicolumn{2}{|c|}{ Middlestream } & \multicolumn{2}{|c|}{ Downstream } \\
\hline & $\begin{array}{l}\text { Correlation } \\
\text { (signal year) }\end{array}$ & time & $\begin{array}{l}\text { Correlation } \\
\text { (signal year) }\end{array}$ & time & $\begin{array}{l}\text { Correlation } \\
\text { (signal year) }\end{array}$ & time & $\begin{array}{l}\text { Correlation } \\
\text { (signal year) }\end{array}$ & time \\
\hline \multirow[t]{2}{*}{ Precipitation } & \multicolumn{2}{|l|}{ None } & Negative(1-3) & $2001-2004$ & Positive(1-4) & $1996-2003$ & Positive(2-4) & $1994-2001$ \\
\hline & & & & & & & Positive (4-6) & 2001-2012 \\
\hline \multirow[t]{2}{*}{ Runoff } & Negative (2-4) & 1988-1993 & Negative(1-3) & 1991-1997 & Positive(2-3.5) & $1998-2002$ & Positive & $1991-1998$ \\
\hline & Negative (1-2) & 1994-1999 & & & & & $(0.5-2.5)$ & \\
\hline \multirow[t]{2}{*}{ Sediment } & Negative(2-3.5) & $1988-1993$ & Positive(1-2) & 1994-1996 & Positive(0.5-3) & $2012-2016$ & Positive(1-4) & $1996-2001$ \\
\hline & Negative(0.5-3.5) & 1994-1997 & & & & & & \\
\hline
\end{tabular}

\section{Runoff coefficient and sediment concentration change with NDVI}

NDVI has a significant correlation with runoff coefficient and sediment concentration at some extent. Specifically, the NDVI shows significant negative change with a signal of 2-4 years mainly in 1988-1993 and 1-2 years in 1994-1999 for upstream Chankou (Fig. 5A) although NDVI doesn't show any significant trends in this period that because the runoff coefficient also influenced by the climate factors. For the upstream Huining, there is also significant negative correlation $(p<0.05)$ with 1-3 years of signal from 1991-1997 (Fig. 5B). Similarly, the results show a signal of 4-6 years for NDVI and runoff coefficient from 1998-2002 in the downstream ZRB (Fig. 5D). However, the relationship between NDVI and runoff coefficient shows a positive correlation with 2-3.5 years in the 1998-2002 in the middlestream ZRB (Fig. 5C). Sediment concentration is negatively correlated to NDVI with a signal of 2-3.5 years, mainly in 1988-1993 and 0.5-3.5 years in 1994-1997 (Fig.5E) in the upstream Chankou, a signal of 1-2 years in 1994-1996, respectively (Fig. 5F), and a signal of 0.5-3 years for NDVI and sediment concentration from 2012-2016 in the middlestream ZRB (Fig. 5G), respectively. For the downstream ZRB, NDVI displays significantly positive correlation $(p<0.05)$ with sediment concentration with a signal of $1-4$ years from 1996-2001 (Fig. 5H).
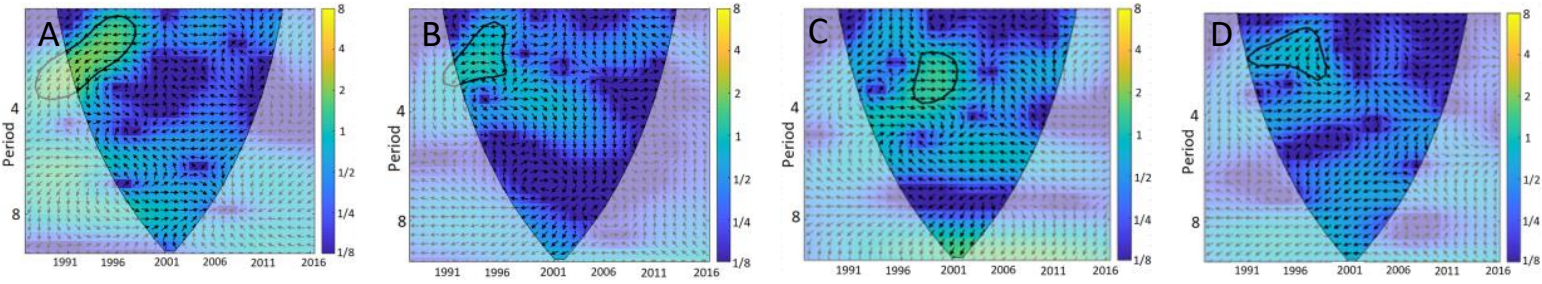

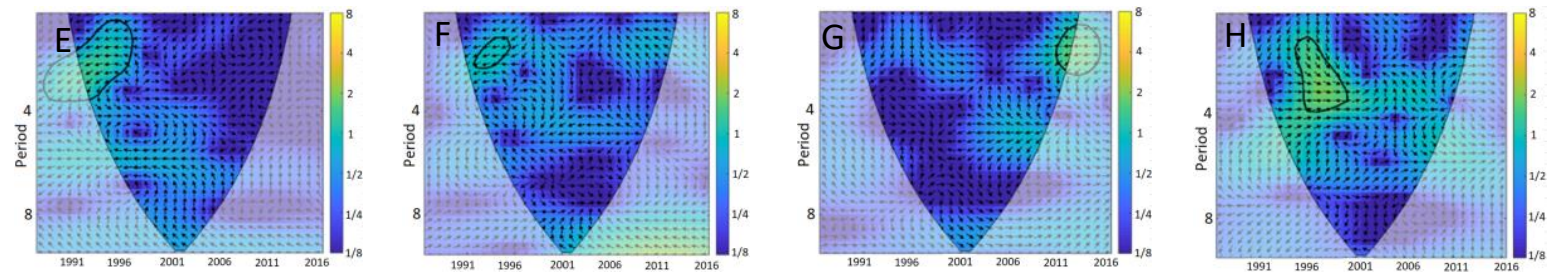

Figure 5. The relationship between annual maximum NDVI and runoff coefficient (A-D) and concentration (EH) detected by cross wavelet method from upstream Chankou, upstream Huining, middlestream, downstream.

\section{DISCUSSION AND CONCLUSION}

The vegetation cover dynamic monitor is of a key step to regulate the terrestrial ecosystem balance and climate system. We extracted 30m resolution yearly maximum Normalized Difference Vegetation Index (NDVI) at growing season based on Google Earth Engine (GEE), and explored the relationship between NDVI and precipitation, runoff coefficient and sediment concentration across Zuli River Basin (ZRB) during 1987-2016.

Our results represent that the annual maximum NDVI shows an increase trend and the mean value from 19872016 shows a large difference in the different parts of catchment. Although the vegetation cover in upstream Chankou and upstream Huining were higher than that in the middlestream and downstream, the increase rate in upstream was lower than that in other parts of ZRB. Before the implementation of GPP, the vegetation covers were mainly dominated by the insignificant change, and there was strong widespread increase in vegetation cover after GPP. The precipitation showed a significant correlation $(p<0.05)$ with NDVI before 2002 in the upstream Huining and middle stream. But this kind of effect is weakening after 2002 due to human activities. The area of upstream Chankou, almost, did not get the obvious effect of precipitation. For the downstream the effect time of precipitation on vegetation cover lasted, however, until 2012 because the soil and water conservation was implemented lately and few in the downstream ZRB were mainly implemented. At the same time, the positive human activities were also regarded as an important factor that contributed to the reduction of runoff and sediment. Hence, for a better development of soil and water conservation measures programme, it is necessary to investigate the causes and effects of vegetation cover change under the global change environment and human disturbance.

\section{ACKNOWLEDGMENTS}

This study was supported by the CAS Pioneer Hundred Talent Program and IGSNRR Supporting Fund (YJRCPT2019-101). We acknowledge Pranesh Paul for proofreading and reviewing this paper.

\section{REFERENCES}

Bao, G., Qin, Z., Bao, Y., Zhou, Y., Li, W., Sanjjav, A. (2014). NDVI-based long-term vegetation dynamics and its response to climatic change in the Mongolian plateau. Remote Sensing, 6(9), 8337-8358. https://doi.org/10.3390/rs6098337

Cao, Z., Li, Y., Liu, Y., Chen, Y., Wang, Y. (2018). When and where did the Loess Plateau turn "green\{"\}? Analysis of the tendency and breakpoints of the normalized difference vegetation index. LAND DEGRADATION \& DEVELOPMENT, 29(1), 162-175. https://doi.org/10.1002/ldr.2852

Chu, H., Venevsky, S., Wu, C., Wang, M. (2019). NDVI-based vegetation dynamics and its response to climate changes at Amur-Heilongjiang River Basin from 1982 to 2015. Science of the Total Environment, 650, 2051-2062. https://doi.org/10.1016/j.scitotenv.2018.09.115

Du, J., Shu, J., Yin, J., Yuan, X., Jiaerheng, A., Xiong, S., ... Liu, W. (2015). Analysis on spatio-temporal trends and drivers in vegetation growth during recent decades in Xinjiang, China. International Journal of Applied Earth Observation and Geoinformation, 38, 216-228. https://doi.org/10.1016/j.jag.2015.01.006

Duan, L., Huang, M., Zhang, L. (2016). Differences in hydrological responses for different vegetation types on a steep slope on the Loess Plateau, China. JOURNAL OF HYDROLOGY, 537, 356-366. https://doi.org/10.1016/j.jhydrol.2016.03.057

Fang, W., Huang, S., Huang, Q., Huang, G., Meng, E., Luan, J. (2018). Reference evapotranspiration forecasting based on local meteorological and global climate information screened by partial mutual information. Journal of Hydrology, 561, 764-779. https://doi.org/https://doi.org/10.1016/j.jhydrol.2018.04.038 
Gorelick, N., Hancher, M., Dixon, M., Ilyushchenko, S., Thau, D., Moore, R. (2017). Google Earth Engine: Planetary-scale geospatial analysis for everyone. Remote Sensing of Environment, 202, 18-27. https://doi.org/10.1016/j.rse.2017.06.031

Huang, C., Yang, Q., Huang, W., Zhang, J., Li, Y., Yang, Y. (2018). Hydrological Response to Precipitation and Human Activities-A Case Study in the Zuli River Basin, China. International Journal of Environmental Research and Public Health, 15(12). https://doi.org/10.3390/ijerph15122780

Jiang, L., Bao, A., Ndayisaba, F., Guli·Jiapaer, Guo, H. (2017). Vegetation dynamics and responses to climate change and human activities in Central Asia. Science of The Total Environment, 599-600, 967-980. https://doi.org/10.1016/j.scitotenv.2017.05.012

Li, A., Wu, J., Huang, J. (2012). Distinguishing between human-induced and climate-driven vegetation changes: a critical application of RESTREND in inner Mongolia. Landscape Ecology, 27(7), 969-982. https://doi.org/10.1007/s10980-012-9751-2

Liu, Y., Guo, Y., Li, Y., Li, Y. (2015). GIS-based effect assessment of soil erosion before and after gully land consolidation: A case study of Wangjiagou project region, Loess Plateau. Chinese Geographical Science, 25(2), 137-146. https://doi.org/10.1007/s11769-015-0742-5

McVicar, T. R., Li, L. T., Van Niel, T. G., Zhang, L., Li, R., Yang, Q. K., ... Gao, P. (2007). Developing a decision support tool for China's re-vegetation program: Simulating regional impacts of afforestation on average annual streamflow in the Loess Plateau. Forest Ecology and Management, 251(1-2), 65-81. https://doi.org/10.1016/j.foreco.2007.06.025

Pang, G., Wang, X., Yang, M. (2017). Using the NDVI to identify variations in, and responses of, vegetation to climate change on the Tibetan Plateau from 1982 to 2012. Quaternary International, 444, 87-96. https://doi.org/10.1016/j.quaint.2016.08.038

Robinson, N. P., Allred, B. W., Jones, M. O., Moreno, A., Kimball, J. S., Naugle, D. E., ... Richardson, A. D. (2017). A dynamic landsat derived normalized difference vegetation index (NDVI) product for the conterminous United States. Remote Sensing, 9(8), 1-14. https://doi.org/10.3390/rs9080863

Wen, Z., Wu, S., Chen, J., Lü, M. (2017). NDVI indicated long-term interannual changes in vegetation activities and their responses to climatic and anthropogenic factors in the Three Gorges Reservoir Region, China. Science of The Total Environment, 574, 947-959. https://doi.org/https://doi.org/10.1016/j.scitotenv.2016.09.049

Xin, Z. B., Xu, J. X., Zheng, W. (2008). Spatiotemporal variations of vegetation cover on the Chinese Loess Plateau (1981-2006): Impacts of climate changes and human activities. Science in China Series D: Earth Sciences, 51(1), 67-78. https://doi.org/10.1007/s11430-007-0137-2

Xin, Z., Yu, X., Li, Q., Lu, X. X. (2011). Spatiotemporal variation in rainfall erosivity on the Chinese Loess Plateau during the period 1956-2008. REGIONAL ENVIRONMENTAL CHANGE, 11(1), 149-159. https://doi.org/10.1007/s10113-010-0127-3

Yao, B., Liu, Q. (2018). Characteristics and influencing factors of sediment deposition-scour in the Sanhuhekou-Toudaoguai Reach of the upper Yellow River, China. International Journal of Sediment Research, 33(3), 303-312. https://doi.org/https://doi.org/10.1016/j.ijsrc.2018.03.003

Zhang, L., Wang, J., Bai, Z., Lv, C. (2015). Effects of vegetation on runoff and soil erosion on reclaimed land in an opencast coal-mine dump in a loess area. CATENA, 128, 44-53. https://doi.org/https://doi.org/10.1016/j.catena.2015.01.016

Zhao, A., Zhang, A., Liu, J., Feng, L., Zhao, Y. (2019). Assessing the effects of drought and "Grain for Green" Program on vegetation dynamics in China's Loess Plateau from 2000 to 2014. Catena, 175(December 2018), 446-455. https://doi.org/10.1016/j.catena.2019.01.013 